\title{
Influence of the Temperature upon the Life Duration and the Growth of the Fibroblast Cultivated in vitro. . $^{*}$
}

\author{
By \\ MAMORU NEMOTO. \\ (根本盛) \\ (From the Physiological Laboratory of Prof. Y. Satake, \\ Tohoku Imperial University, Sendai.)
}

Since it was found by van't $\mathrm{H}$ off-Cohe $\mathrm{n}^{\mathrm{t}}$ that within certain limits of temperature van't Hoff's law of chemical reaction (Kanitz's RGTlaw) is applicable to plant respiration also, numerous experiments have been made to find some definite relationship between temperature and biological processes and to examine whether it could be identified with any chemical law.2

There is no doubt that temperature has great influence on biological processes; the question at present seems to be whether the temperature effect can be expresscd by a curve with exponential characters, ${ }^{2}$ by a straight line, or by some any other curve.

Tissues cultivated in vitro are a very good subject to work with on this point, because of the ease of control of the conditions and the relative simplicity of measurement of growth.

Not only is it important to investigate the temperature effect on the growth of tissue in vitro with a view to a physico-chemical explanation of growth but also from a practical and techinical point of view. Fischer ${ }^{4)}$

$\$$ This work was done under suggestion and direction of Dr. K odama, formerly Assistant Profestor of this laboratory and now, Professor of Physiology at Kumamoto.

* The essentials of this paper were presented before the Serenth Meeting of the Japanese Physiological Society at Kyoto, in April 1925.

1) Studien zur chemischen Dynamik, Amsterdam u. Leipzig 1896, 129. Nach T. II. van't $\mathrm{H}$ off's Études de Dynamique Chimique bearbeitet ron E. Cohen. Cited from : A. Kanitz, Temperatur u. Lebensvorgänge, Berlin 1915.

2) See reviews in : A. Pütter, Zeitschr. f. allg. Physiol, 1914, 16, 574; A. Kanitz, Temperatur u. Lebensrorgänge, Berlin 1915.

3) A. Krough, Zeitschr. f. allg. Physiol., 1914, 16, 168 u. 178.

4) A. Fischer, Arch. f. exp. Zellforsch., 1926, 2, 804. 
found that the fibroblast which was kept at room temperature $\left(20^{\circ}\right)$ in the dark lived at least three weeks. This is really a great discovery in the technique of tissue culture, because one is thus not necessarily required to be nervous about keeping the tissue at normal physiological temperature and one can escape enormous trouble in keeping the tissue permanently alive by changing the culture medium every second day.

It is necessary to examine the influence of temperature on the tissue in vitro more systematically. In this paper are presented the results of the experiment which was undertaken in order to make some contribution to this problem.

\section{METHoD.}

The hanging-drop method developed by Carrel and his pupils was used in this experiment. Preparation of the plasma of chicken and the embryonic tissue juice was done in pursuance of the method which was described by Fischer.5) Usually the tissue juice was prepared fresh every time it was to be used, but sometimes diluted extract was also employed in the experiment.

Care was taken to obtain an equal area of the medium on the mica slip with the help of a circle drawn on the paper under the slip, to avoid any possible error owing to difference of the thickness of the midium.

The measurement of growth was made by tracing the outline of the new growth and the original fragment itself on a sheet of paper by means of a microscope provided with a drawing prism. The drawn area was measured with a planimeter and expressed in square centimetres.

The degree of growth at any time was shown by the ratio of the total area after growing and the area of the original fragment.

\section{EXPERIMENTS.}

I. On the Latent Period.

The latent periods of growth at early passages were observed by the way, independently of the temperature experiment. Some examples may be quoted here.

To determine a latent period which covered the time from the inoculation of the fragment into the culture medium until the appearance of

5) A. Fischer, Tissue Culture, Copenhagen 1925, 82, ff. 
the first cells, note must be taken of the appearance of the new cells immediately after the preparation of the last passage.

Carrel and Burrow ${ }^{6)}$ demonstrated that the period of latency varied according to the age of the animal supplying the fragment and to some other conditions; namely, in the case of a six days old kitten the growth of the thyroid fragment in the plasmatic medium began in 12 hours; in that of a young dog it began after 24-48 hours and in the case of adult animals, $2-3$ years old, the latent period extended to $48-72$ hours.

In my case, starting from a fragment of embryonic heart muscle, at the first passage the latent period was found to be 9 to 11 hours, for instance, plate 3625 was prepared at $2^{11} 17^{\prime} \mathrm{p} . \mathrm{m}$. on the 21 st of December 1927 and the new cells began to appear at $11^{\mathrm{h}} 34^{\prime}$ p.m. of the same day, therefore the period of latency extended to 9 hours and 17 minutes.

At the second passage the latent period diminished a little and was found as 8 to 9 hours; for instance, it took place for the second passage of plate 3910 at $2^{\text {h }} 15^{\prime}$ p.m. on the 30th of December and when it was observed at $9^{\prime \prime} 37^{\prime}$ p.m. on that day, the culture had not begun to grow, but at $10^{\mathrm{h}}$ $40^{\prime}$ p.m. the beginning of the growth could be diagnosed by the appearance of the very faint new proliferated cells radiating towards the medium from the sharp edges of the fragment, so that the latent period in the second passage was shorter than that of the first.

At the third passage, the latent period was 6 to 7 hours. In plate 3872 it was appreciated as $6 \frac{1}{2}$ hours. At the fourth passage it was found as 5 to 7 hours, namely in plate $3695,5 \frac{3}{4}$ hours, in plates 3869 and 3867 $6 \frac{3}{4}$ hours and 7 hours and 6 minutes respectively.

At the fifth passage the period of latency became shorter and was appreciated as 5 to 6 hours. In plate 3928 it was found to be 5 hours and 25 minutes. From these observations it may be concluded that the more passages the culture undergoes, the shorter becomes the latent period of growth to some extent.

Similar observations were made by Carrel and Burrows, viz. that a fragment of a thyroid gland derived from the dogs, from 8 months to 2 years old, commenced in the first passage to grow with a period of latency of ca. 48 hours in the plasmatic medium, but in the second passage, which was made at the interval of 5 or 8 days, the latent period diminished to 12 hours.

After the first, the second, and rarely the third pasage, there was observed the pulsation of the fragment of the cultivated heart muscle and the passive movement of the cells

6) A. Carrel and M. T. Burrows, Journ. Exp. Med., 1911, 13, 418.

7) A. Carrel and M. T. Burrows, Com. Rend. d. I. Soc. d. Biol., 1910, 69, 329. 
surrounding the original fragtuent, as a whole or partly, with the rhythm of 6 to 98 per minute at $39^{\circ}$.

It was often observed that in a fragment of the cultivated heart muscle two pulsating parts were cut of by the non-pulsating tissue, and mortover the two parts pulsated with a different rhythm, for instance in plate 108 one with the rhythm of 98 per minute and the other with that of 18 per minute at $39^{\circ}$.

Ebeling ${ }^{8}$ stated that the cultures of heart tissue derived from a 7 days old chick embryo pulsated after 104 days of life in vitro, when the cultures were transferred every few days to a fresh medium which was composed of two drops of the hypotonic chick plasma plus one drop of the fresh embryonic extract.

But at the beginning of his experiments, the author employed as a culture medium only hypotonic chick plasma and the pulsation of the heart tissue disappeared during the early passiges to reappear in the fifteenth passage.

Carre $1^{m}$ demonstrated also that the fragnents of a heart pulsated thythmically till the beginning of the third month of their life in ritro. In his experiment hypotonic plasm: alone was used as a culture medium. After the second passage there were no rhythmical contractions until the twelfth, but the pulsation began to reappear after the thirteenth passage till the beginning of the third month.

\section{Effect of Diluted Embryonic Extract.}

As already mentioned, I employed sometimes the diluted embryonic extract of Tyrode solution instead of the embryonic tissue juice itself for the composition of the culture medium, generally at the first to third passage, so that I compared the effects of both on the growth of the fibroblast in vitro.

The Tyrode extract was obtained from Tissnepulp-Tyrode mixture which had been kept in the ice box for two days. The Tyrode solution added was one third of the volume of the embryouic tissue pulp.

The results are summarized in Tables I and II.

In this comparison the cultures at the same passage are derived from the one and the same origin and the initial sizes of the fragments and the total areas of the cultures are outlined at the same time.

At the first passige the moan values of the initial sizes of the fragments and that of the total areas were appreciated as 2.4 and $21.0 \mathrm{sq} . \mathrm{cm}$. respectively in the culture media composed of the plasma and the non diluted embryonic juice after the lapse of 81 hours from the inoculation; therefore the mean degree of the growth i. e. the mean value of the total areas divided by the initial sizes of the fragments was estimated as 8.6 .

While in the same pasiage, when the diluted extract was used to prepare the culture media, mean values of the initial fragments and that of

\footnotetext{
8) A. IT. Ebeling, Journ. Exp. Med., 1913, 17, 274.

9) A. Carrel, Joum. Exp. Med., 1912, 15, 588.
} 
TABLE I.

Degree of grouth of the cultures in the culture media composed of the equal rolume of the plasma and the not diluted embryonic tissue juice.

\begin{tabular}{|c|c|c|c|c|c|c|c|c|c|}
\hline 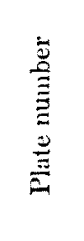 & 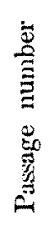 & Date & 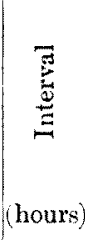 & 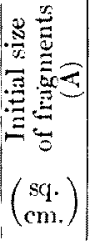 & 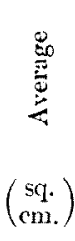 & 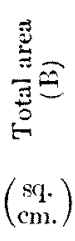 & 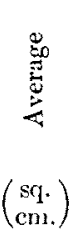 & $\left(\frac{B}{A}\right)$ & 总 \\
\hline $\begin{array}{l}3528 a \\
3528 b \\
3530 a \\
3530 b \\
3531 a \\
3531 b\end{array}$ & $\begin{array}{l}\mathrm{I} \\
" \\
" \\
" \\
"\end{array}$ & $\begin{array}{c}1^{\mathrm{ls}} \text { p.m. 16. XII. 1927 } \\
", \\
", \\
", \\
", \\
"\end{array}$ & $\begin{array}{l}81 \\
" \\
" \\
" \\
" \\
"\end{array}$ & $\begin{array}{l}2.5 \\
2.0 \\
2.9 \\
1.4 \\
2.4 \\
3.3\end{array}$ & 2.4 & $\begin{array}{r}16.0 \\
18.1 \\
37.5 \\
9.8 \\
25.8 \\
19.5\end{array}$ & 21.0 & $\begin{array}{r}6.4 \\
9.0 \\
12.9 \\
7.0 \\
10.5 \\
5.9\end{array}$ & $\$ .6$ \\
\hline $\begin{array}{l}3725 a \\
3725 b \\
3726 a \\
3726 b \\
3727 a \\
3727 b \\
3729 a \\
3729 b\end{array}$ & $\begin{array}{l}\text { II } \\
", \\
", \\
", \\
",\end{array}$ & $\begin{array}{c}11^{\mathrm{h}} \text { p.m. 23. XII. } 1927 \\
", \\
", \\
", \\
", \\
", \\
", \\
"\end{array}$ & $\begin{array}{l}70 \\
", \\
" \\
", \\
", \\
"\end{array}$ & $\begin{array}{l}4.8 \\
5.6 \\
2.6 \\
3.1 \\
3.7 \\
4.1 \\
4.3 \\
4.2\end{array}$ & 4.0 & $\begin{array}{l}25.8 \\
25.8 \\
21.6 \\
24.5 \\
18.8 \\
24.8 \\
34.9 \\
29.4\end{array}$ & 25.7 & $\begin{array}{l}5.4 \\
4.6 \\
8.3 \\
7.9 \\
5.1 \\
6.0 \\
8.1 \\
7.0\end{array}$ & 6.5 \\
\hline $\begin{array}{l}3947 a \\
3947 b \\
3949 a \\
3948 b \\
3949 a \\
3949 b \\
3950 a \\
3950 b \\
3951 a \\
3951 b \\
3952 a \\
3952 b\end{array}$ & $\begin{array}{l}\text { III } \\
" \\
" \\
" \\
" \\
" \\
" \\
" \\
" \\
"\end{array}$ & 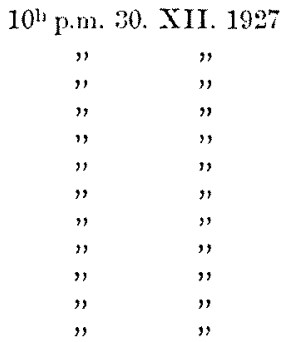 & $\begin{array}{l}69 \\
", \\
", \\
", \\
", \\
", \\
", \\
",\end{array}$ & $\begin{array}{l}2.1 \\
2.2 \\
2.6 \\
2.7 \\
4.3 \\
3.8 \\
2.7 \\
2.5 \\
1.8 \\
1.9 \\
2.5 \\
2.5\end{array}$ & 2.6 & $\begin{array}{l}29.9 \\
37.6 \\
43.8 \\
45.1 \\
38.9 \\
43.9 \\
21.4 \\
20.2 \\
20.6 \\
19.9 \\
53.1 \\
42.2\end{array}$ & 34.5 & $\begin{array}{r}14.2 \\
17.1 \\
16.6 \\
17.8 \\
7.9 \\
11.5 \\
7.9 \\
8.1 \\
11.4 \\
10.5 \\
21.2 \\
16.9\end{array}$ & 18.4 \\
\hline
\end{tabular}

The letters $a$ and $b$ put on the plate number indicate that the two fragments of the tiswe were cultivated in the same culture medium.

the total areas were appreciated as 2.1 and $27.7 \mathrm{sq} . \mathrm{cm}$. respectively after the same interval of time, and the mean degree of the growth was found as 13.6.

The degree of growth was larger in the latter case.

In the second passage, when the embryonic juice was employed, the mean value of the initial fragments and that of the total areas amounted to 4.0 and $25.7 \mathrm{sq} . \mathrm{cm}$. respectively after 68 hours from the passage, therefore 


\section{TABLE II.}

Degree of growth of the cultures in the culture media composed of the equal rolume of the plasma and the

diluted embryonic extract.

\begin{tabular}{|c|c|c|c|c|c|c|c|c|c|}
\hline 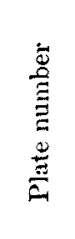 & 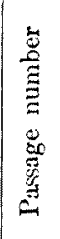 & Dite & $\left(\begin{array}{l}\overrightarrow{5} \\
\stackrel{5}{ \pm} \\
\text { (hours) }\end{array}\right.$ & 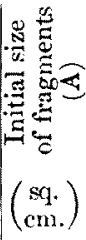 & 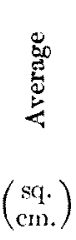 & 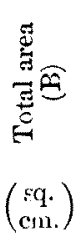 & 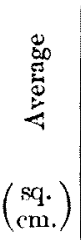 & 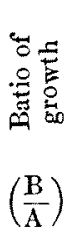 & 岕 \\
\hline $\begin{array}{l}3524 a \\
3524 b \\
3525 a \\
3525 b\end{array}$ & $\begin{array}{l}\text { I } \\
" \\
" \\
"\end{array}$ & $\begin{array}{c}1^{13} \text { p.m. 16. XII. } 1927 \\
" \\
" \\
"\end{array}$ & $\begin{array}{l}81 \\
" \\
"\end{array}$ & $\begin{array}{l}1.5 \\
2.3 \\
1.9 \\
2.6\end{array}$ & 2.1 & $\begin{array}{l}25.9 \\
30.2 \\
23.0 \\
31.6\end{array}$ & 27.7 & $\begin{array}{l}17.3 \\
13.1 \\
12.1 \\
12.1\end{array}$ & 13.6 \\
\hline $\begin{array}{l}3735 a \\
3735 b \\
3737 a \\
3787 b \\
3738 a \\
3738 b\end{array}$ & $\begin{array}{l}\text { II } \\
" \\
" \\
" \\
",\end{array}$ & $\begin{array}{cc}11^{11} \text { p.m. 23. XII. 1927 } \\
", & " \\
" & " \\
" & " \\
" & "\end{array}$ & $\begin{array}{l}70 \\
" \\
" \\
" \\
"\end{array}$ & $\begin{array}{l}2.7 \\
2.6 \\
2.6 \\
2.9 \\
2.1 \\
4.2\end{array}$ & 2.8 & $\begin{array}{l}19.6 \\
18.9 \\
12.6 \\
14.5 \\
16.0 \\
21.2\end{array}$ & 17.1 & $\begin{array}{l}7.2 \\
7.3 \\
4.8 \\
5.0 \\
7.6 \\
5.0\end{array}$ & 6.1 \\
\hline $\begin{array}{l}3953 a \\
3958 b \\
3954 a \\
3954 b \\
3955 a \\
3955 h \\
3956 a \\
3956 b \\
395 i a \\
3957 b\end{array}$ & $\begin{array}{l}\text { II I } \\
", \\
" \\
" \\
" \\
" \\
" \\
" \\
"\end{array}$ & 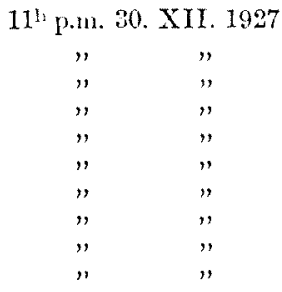 & $\begin{array}{l}68 \\
" \\
" \\
" \\
" \\
" \\
" \\
" \\
"\end{array}$ & $\begin{array}{l}3.7 \\
3.3 \\
4.4 \\
3.5 \\
3.9 \\
3.7 \\
4.5 \\
3.9 \\
3.5 \\
3.1\end{array}$ & 8.8 & $\begin{array}{l}38.6 \\
37.4 \\
55.8 \\
61.1 \\
56.6 \\
54.6 \\
55.0 \\
62.9 \\
35.9 \\
35.4\end{array}$ & 39.3 & $\begin{array}{l}10.4 \\
11.8 \\
12.7 \\
16.1 \\
14.5 \\
14.7 \\
12.2 \\
16.0 \\
10.2 \\
11.4\end{array}$ & 12.9 \\
\hline
\end{tabular}

the degree of growth was determined as 6.5 , while in the case in which the diluted extract was used, the mean initial size of the fragments and that of the total areas were found as 2.8 and $17.1 \mathrm{sq} . \mathrm{cm}$. respectively, therefore the degree of growth was 6.1. So in the second passage the degrees of growth were almost the same in both cases.

In the third passage, employing the embryonic juice, the mean values of the initial widths of the fragments and that of the total areas were estimated as 2.6 and $34.5 \mathrm{sq}$. cm. respectively after an interval of 69 hours, the degree of growth being 13.4, while the mean values of the initial sizes of the fragments and that of the total areas were appreciated as 3.8 and $39.3 \mathrm{sq} . \mathrm{cm}$. respectively after 68 hours from the inoculation, when the culture media were prepared by means of the diluted extract; thereforc the 
degree of growth was found as 12.9 , being almost the same value as the former.

Strictly the comparison should have been made with two halves sectioned from one fragment, but from the experiments above quoted it could be concluded that the degree of growth was almost the same even when these two kinds of food material were employed separately to prepare the culture media.

Carrel and Ebeling ${ }^{10}$ observed that after the concentration of the embryonic juice in the medium had reached $40 \%$, no further increase of growth occurred at any higher concentration.

I obscrve here that the diluted extract of the embryonic tissuc is not different from the non-diluted embryonic juice in its effect on the growth of the tissue. From this fact it can be said that the quantity of food material over a certain limit has not especially a more growth-provoking effect on the tissue cells in vitro.

\section{Degree of Growth at Various Temperatures.}

Temperatures investigated were $5^{\circ}, 12^{\circ}, 20^{\circ}, 30^{\circ}, 39^{\circ}$ and $45^{\circ}$.

The temperature variation of the incubators was $0.5^{\circ}$ to $2^{\circ}$.

The tissue to be experimented on was derived in the usual way from the heart muscle of the chicken embryo which was used to make embryonic tissue juice, and it underwent five to seven passages before the actual $c x-$ periment.

After final preparation of the cultures, they were placed in the incubator of $39^{\circ}$ for one day in order to be examined as to whether the tissues were in gocd condition, and if they were found to be good, the outlines of the new growths during this one day and of the original fragments were traced, and then the cultures were distributed into the incubators at various temperatures.

In every medium, one fragment of the tissue was cultivated or two together, in order to compare the degree of growth and the life duration in vitro of the two kinds of cultivation at the same temperature.

The outlines of the total areas of the cultures were traced every day and expressed in square centimeters.

The total areas obtained before the distribution into the various incubators were regarded as the standard area of the corresponding cultures.

10) A. Carrel and A. H. Ebeling, Journ. Exp. Med., 1921, 34, 336. 
The degree of growth for each day was expressed by the ratio of the total area of that day to the standard area. The results are summarized in 'Tables III-VIII.

Of the averages of all fragments at each temperature, the maximum degree of growth at $45^{\circ}$ was 1.7 (on the second day), at $39^{\circ} 5.7$ (on the eighth day), at $30^{\circ} 2.2$ (on the tenth day), that is the largest degree of growth was at $39^{\circ}$, the next at $30^{\circ}$ and the smallest was at $45^{\circ}$. At $20^{\circ}$, $12^{\circ}$ and $5^{\circ}$, there could not be seen any growth at all, whether one fragment was cultivated in one medium or two together. Now some details will be given as follows :-

\section{(1) $45^{\circ}$.}

The mean degrees of growth on

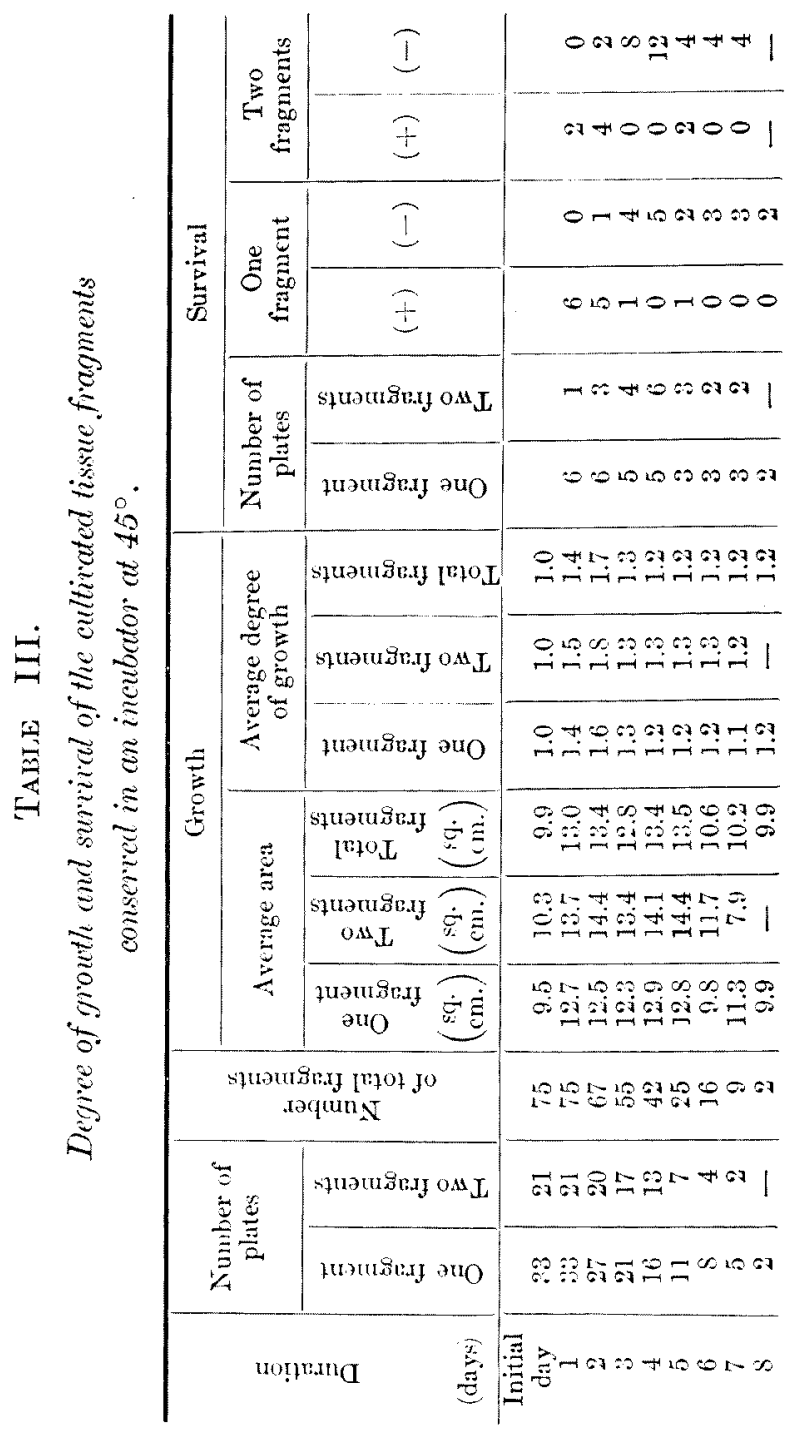
the first and the second day, that is 1.4 and 1.7 respectively, were larger than those at $30^{\circ}$, probably owing to the fact that cultures $1636,1637,1705,1888,1884,1936,2466 \mathrm{a}$ and $246(6)$ had been kept in the incubator where the temperature had varied between $43^{\circ}$ and $44^{\circ}$.

Many cultures reached their maximum growth on the second day, 


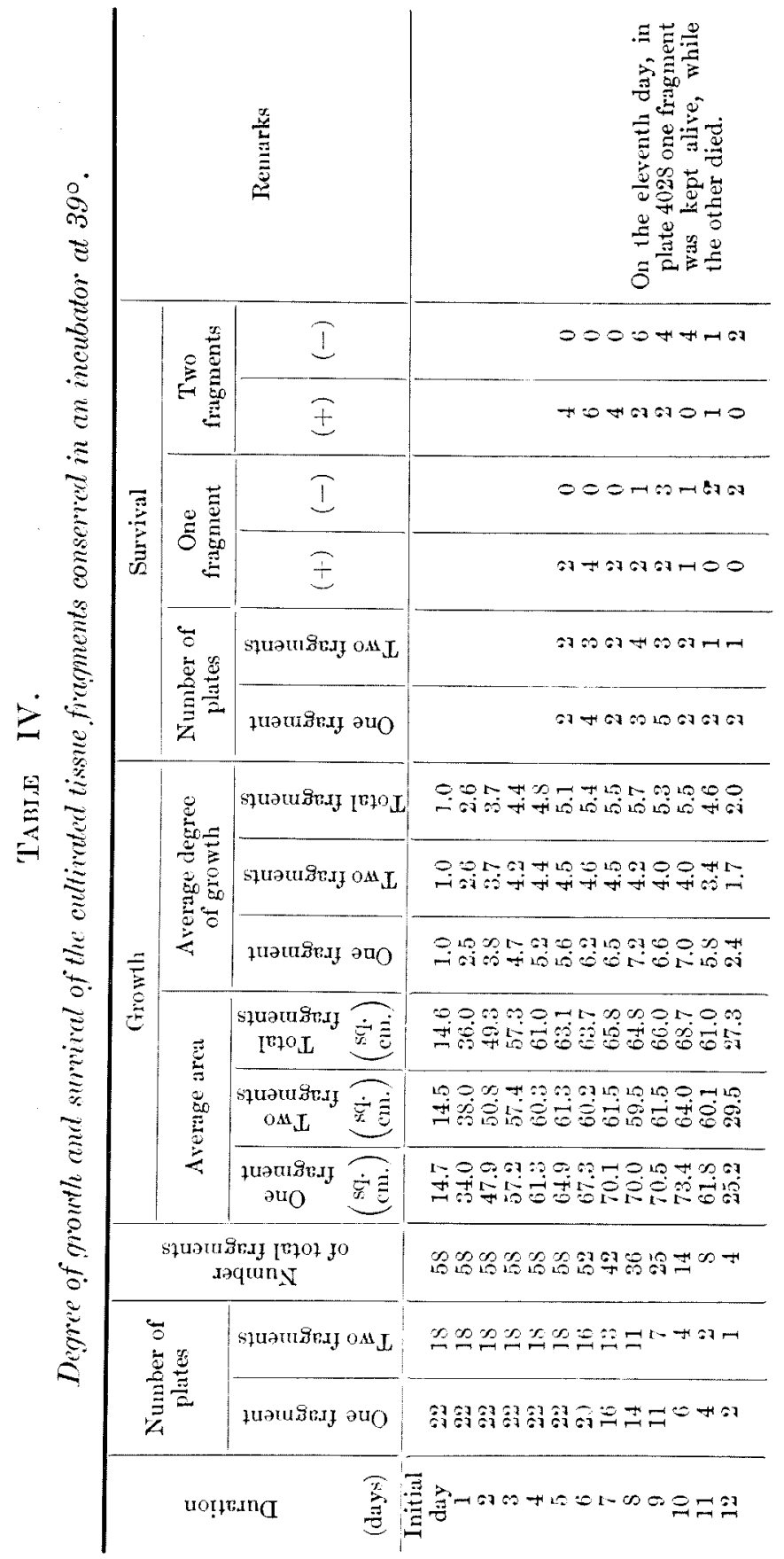




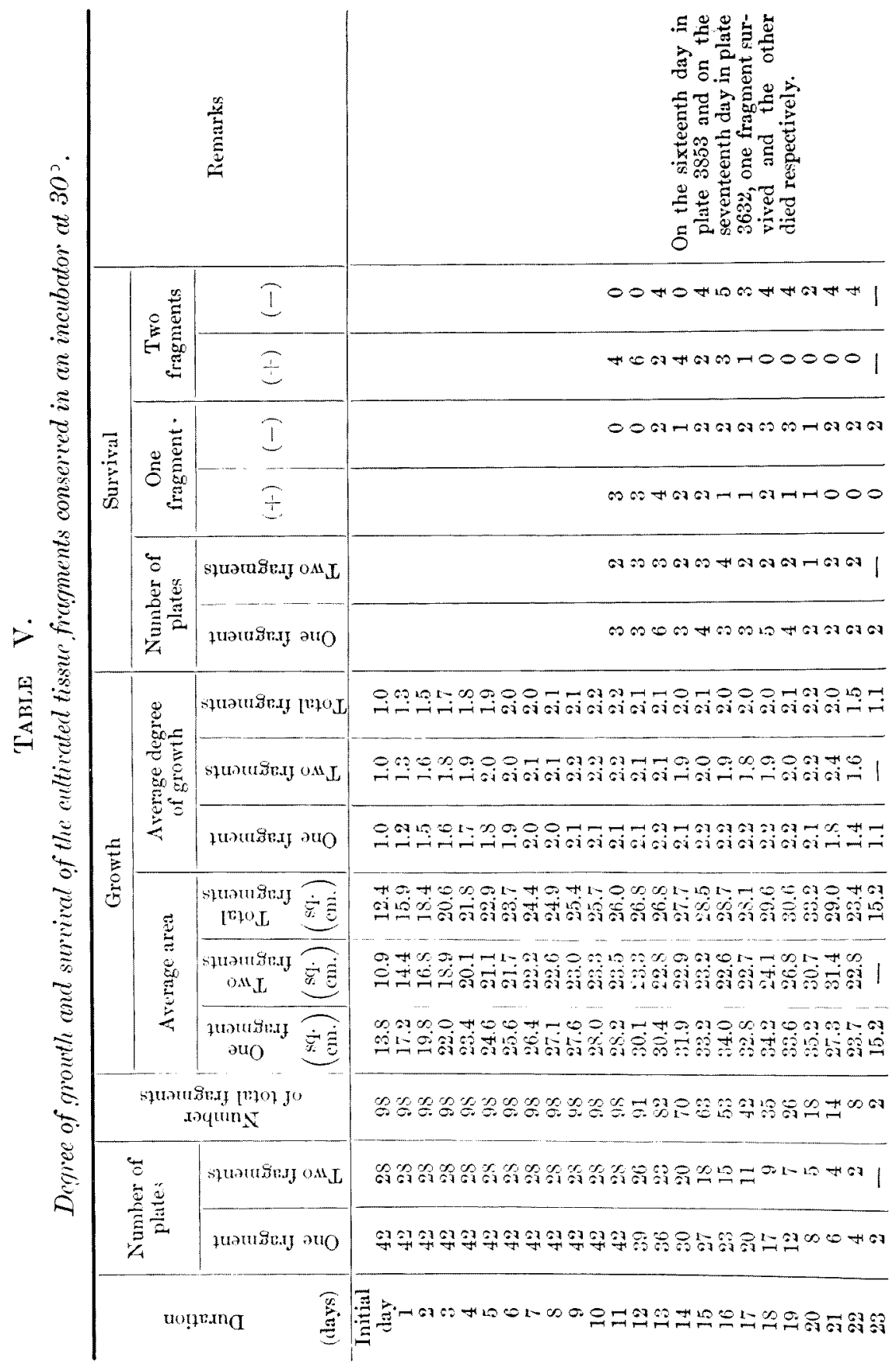




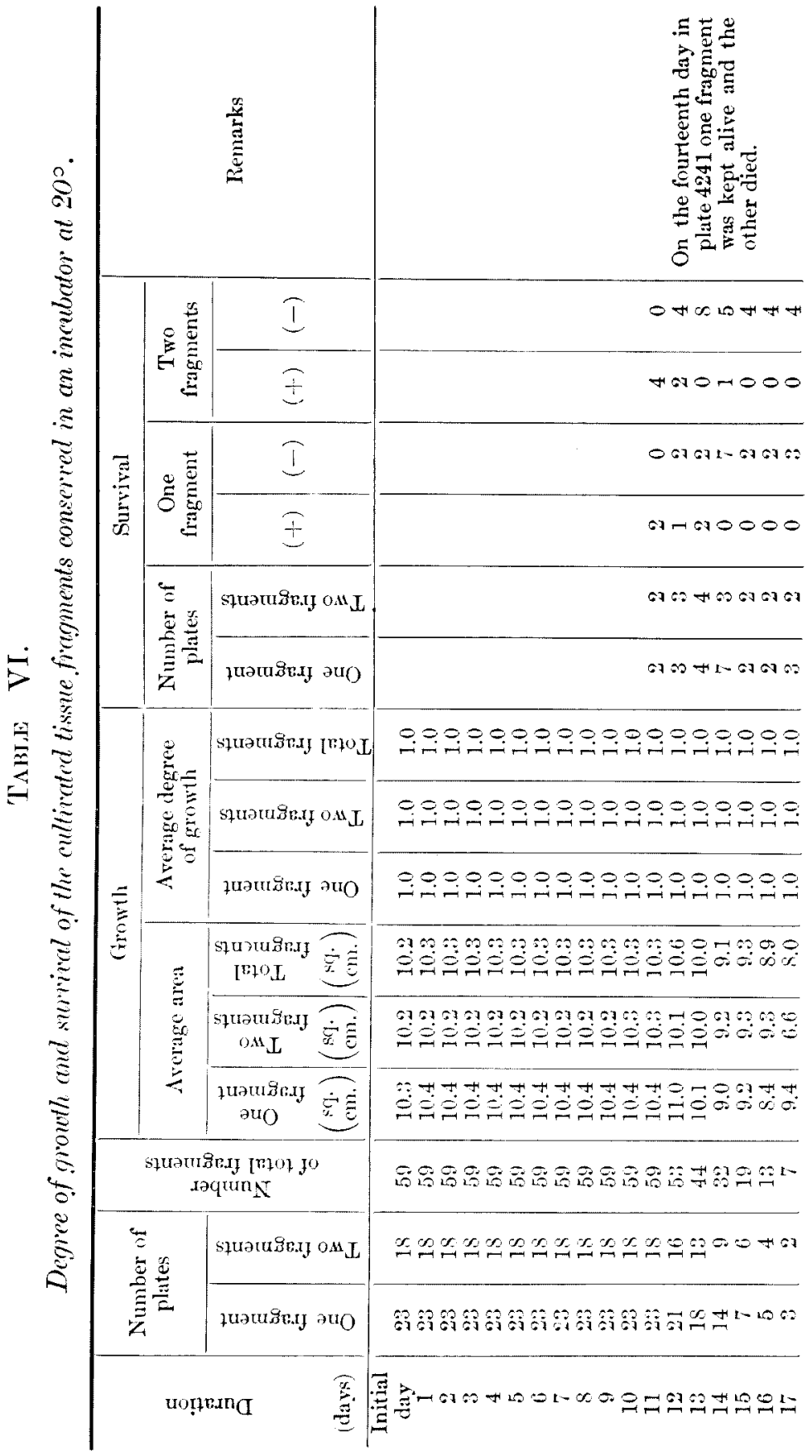




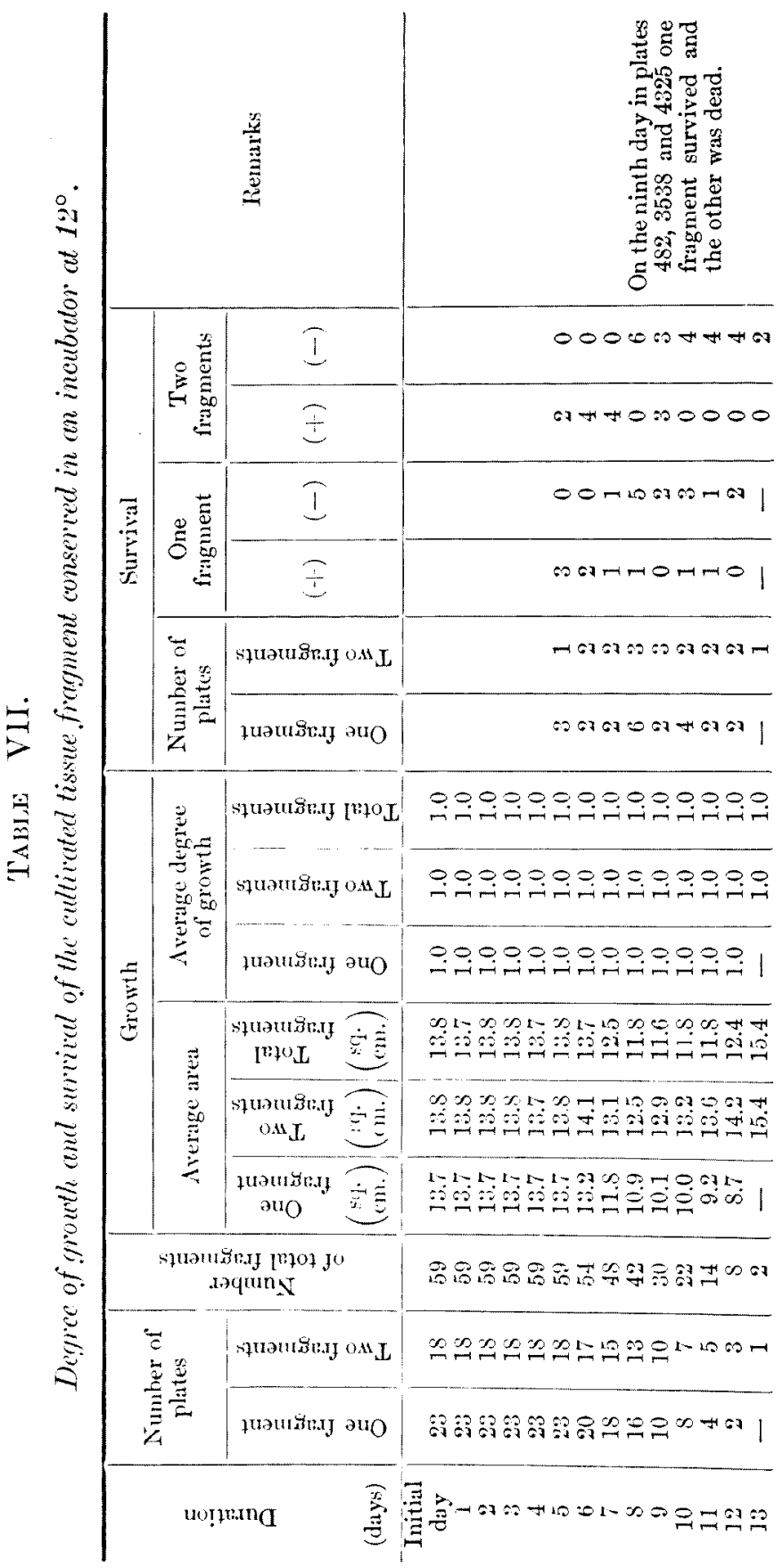




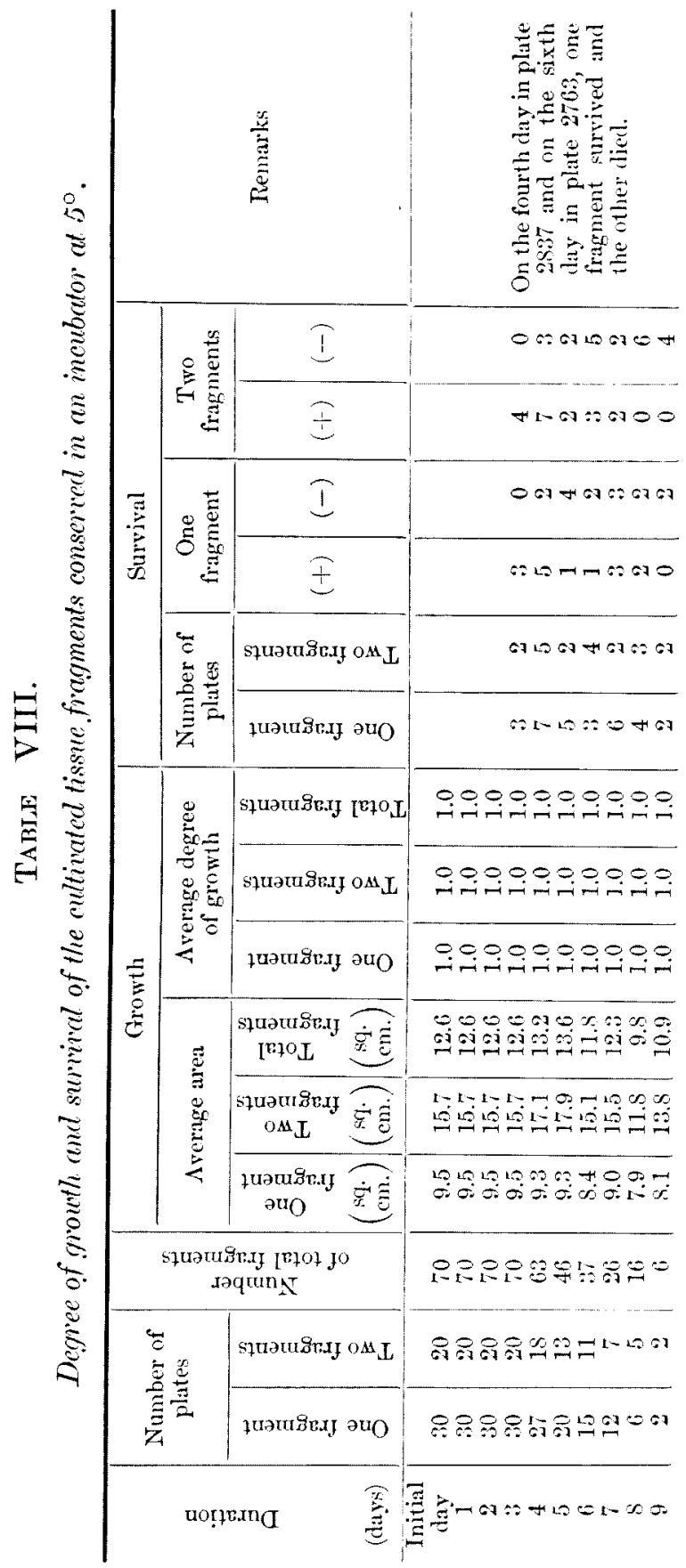

though a few did so on the third or the fourth day, and thereafter they maintained their width unchanged.

For example, the culture in plate 227. attained its maximum growth on the third day, i. e. the total area and the degree of growth were $10.9 \mathrm{sq}$. cm. and 1.2 respectively, and no further growth occurred.

In the cases where two fragments were cultivated together in one medium, I compared the degree of their growth and expressed the difference by the ratio of their degrees minus one.

In plates 969 , 2492, 2834, 2766, 2767,2903 and 2904 the difference was zero, that is, two cultures grew in the same degree in these plates, and in other plites the difference amounted to 0.01 0.21 . In plate 974 , it became exceptionally large and was appreciated as 0.8 . 
In the cases in which one fragment was cultivated in each medium, the degree of growth was almost the same, as compared with that of two fragments cultivated in the same medium.

(2) $39^{\circ}$.

The number of cultures experimented was 18 with two fragments and 22 with one fragment. The smallest degree of growth and the largest were 1.4 (plate $3846 b$ on the third day) and 9.3 (plate $963 b$ on the sixth day) respectively in the case where two fragments were cultivated together, and 1.9 (plate 4105 on the fifth day) and 20.1 (plate 504 on the eighth day) respectively in the case where one fragment was cultivated in one medium.

The curves of the degree of growth referring to days as abscissa were somew hat different according to whether one fragment was cultivated in one medium or two together.

i) Three types of curves were observed in the cases with one fragment in one medium. The first type was a snooth arc shape somewhat like a logarithmic curve. (See Fig. 1 p. 626).

The beginning of the curve was relatively steep, but as the time advanced its inclination to the abseissa became smaller and smaller until the curve reached its maximum height between the second to the tenth day, and thereafter it maintained its height unchanged.

Many cultures grew according to this type.

The second type was an everted S-shaped curve, as can be easily conjectured from the data of the degrees of growth in plate 1201, in which a single tissue fragment grew on the first, the second, the third, the fourth, the fifth, the sixth, the seventh, the eighth and the ninth day with the degrees of $1.6,1.9,2.0,2.1,3.0,4.1,5.2,6.9$ and 8.8 respectively.

The third type was on the whole like the first type, but the ascending part of the curre had a zigzag form.

For example, in plate 379 the cultures grew on the first day with the larger degree of 4.3 , on the second with the degree of 4.5 , i. e. the degree of the growth on this day was very small, on the third day it grew again with the larger degree of 8.1 and on the fourth the augmentation of the total area was represented by the smaller degree of 8.7 , but on the fifth day it grew again with the larger degree of 10.6 , the maximum degree, and on the sixth day it remained at the same area.

ii) In the cases in which two fragments were cultivated together in one medium, the type of the curve which represented the degrees of growth belonged to the first type above mentioned, attaining to the maximum height, which was much smaller than that in the cases with one fragnent in one medium, on the second to the sixth day and then remaining at the same height.

In this case the difference in the degrees of growth of each fragmont in the same medium was appreciated as 0.02 to 0.55 on the last day of the life duration in vitro, except in plate 4025 where it was found as zero.

The interval of time, in which each fragment in the same medium reached the maximum width of its area was different. For example in plate 4032 one fragment reached the maximum width on the fourth day, but the other attiined to the maximum growth on the fifth day.

Whether the above three types of curre showed essentially the types of grow ths in vitro or only accidental ones could not be easily decided, as the examples were not sufficiently 
numerous. In the cases with two fragments in one medium, the growth in the early period (the first 3 days) was the same as the cases with one fragment in one medium, but later the growth of the former fell gradually behind, as is seen from Table IV.

This might be due to the lack of oxygen in the chamber where the tissue existed or to the rapid accumulation of metabolic products. Later this point will be touched on again (p. 633).

(3) $30^{\circ}$.

The number of the cultures experimented on was 28 with two fragments and 42 with one fragment.

Of the maximum growths attained here, the smallest and the largest degree were $1.0(3635 b, 3925 b$, that is-no growth) and $8.3(972 a$ on the ninth day) respectively in the cases with two fragments in one medium and 1.1 (3686, 3691 on the second, 3470 and 3654 on the third day) and 7.2 (622 on the thirteenth day) respectively in the cases with one fragment in one medium.

Here the fragment of the tissue grew with a very slowly augmented but long lasting rate.

The type of the curve representing the degree of growth was the same, whether one fragment was cultivated in a medium or two together.

While it is true on the one hand that, when two fragments were embedded in a medium, the degrees of growth of each fragment were quite the same (for instance, in plate 3771 two fragments, 2.1 and $1.6 \mathrm{sq} . \mathrm{cm}$. in their initial sizes, augnented their widths at almost the same rate of growth and in the last day the difference in the degree of their growth was zero. The same phenomena were observed in plates $2052,3769,3851,3636$ and 3471), on the other hand it was not overlooked that one fragment of two cultivated together in a medium grew with a larger degree than that of the other.

The difference of the degrees of growth of the two fragments was found as, generally, 0.02 to 0.32 on the last day of the life in vitro, but in plates 972 and 3682 it was very large and appreciated as 0.84 and 1.08 respectively.

In the group of $30^{\circ}$ some tissue cells grew constituting a macroscopical concentric circle like an annual ring.

There seemed to exist some relationship betwecn this concentric ring and the rate of growth. In a certain period of the life in vitro the rate of growth became very slow, or the tissue cells ceased to grow and then began to multiply with the larger rate.

In plate 3632 , for instance, one fragment out of the two showed the phenomenon above mentioned. Having been calculated as $6.1 \mathrm{sq} . \mathrm{cm}$. in the in itial total area, the fragment grew after the first day to $8.6 \mathrm{sq}$. cm., i. e. the degree of growth was 1.4 , after the second day to $9.3 \mathrm{sq} . \mathrm{cm}$, with the degree of 1.5 , after the third to $9.6 \mathrm{sq} . \mathrm{cm}$., i. e. the degree of growth 1.6 , from the fourth to the eleventh day it grew only from $9.7 \mathrm{sq} . \mathrm{cm}$. to $11.5 \mathrm{sq} . \mathrm{cm}$., with the degree from 1.6 to 1.9 during 8 days. On the twelveth day the total area of the fragment grew to $13.1 \mathrm{sq}$. $\mathrm{cm}$. with the greater degree of 2.1 and ceased to grow till the fourteenth day, constituting a darkish, macroscopical concentric ring. From the fifteenth to the 
seventeenth duy it grew again from 15.3 to $16.4 \mathrm{sq} . \mathrm{cm}$., in other words with the degree of 2.5 to 2.7. Thus the brighter concentric ring was made again during the lapse of this interval.

Whether these ring phenomena have any relation with $F$ ischer'si) observation about the periodical mitotic cell divisions is of course very difficult to decide.

As an example of growth types at various temperatures the degrees of growth of the tissue fragments derived from the same origin were traced in Fig. 1. They were cultivated every two together in one medium. (Plate 4239 at $5^{\circ}, 4246$ at $12^{\circ}, 4241$ at $20^{\circ}, 4243$ at $30^{\circ}, 4242$ at $39^{\circ}$ and 4240 at $45^{\circ}$ ).

Fig. 1.

Degree of growth fo the cultwe, having the same origin and being inoculated with two fratments logether in eaeh medium, at rarious temperatures.

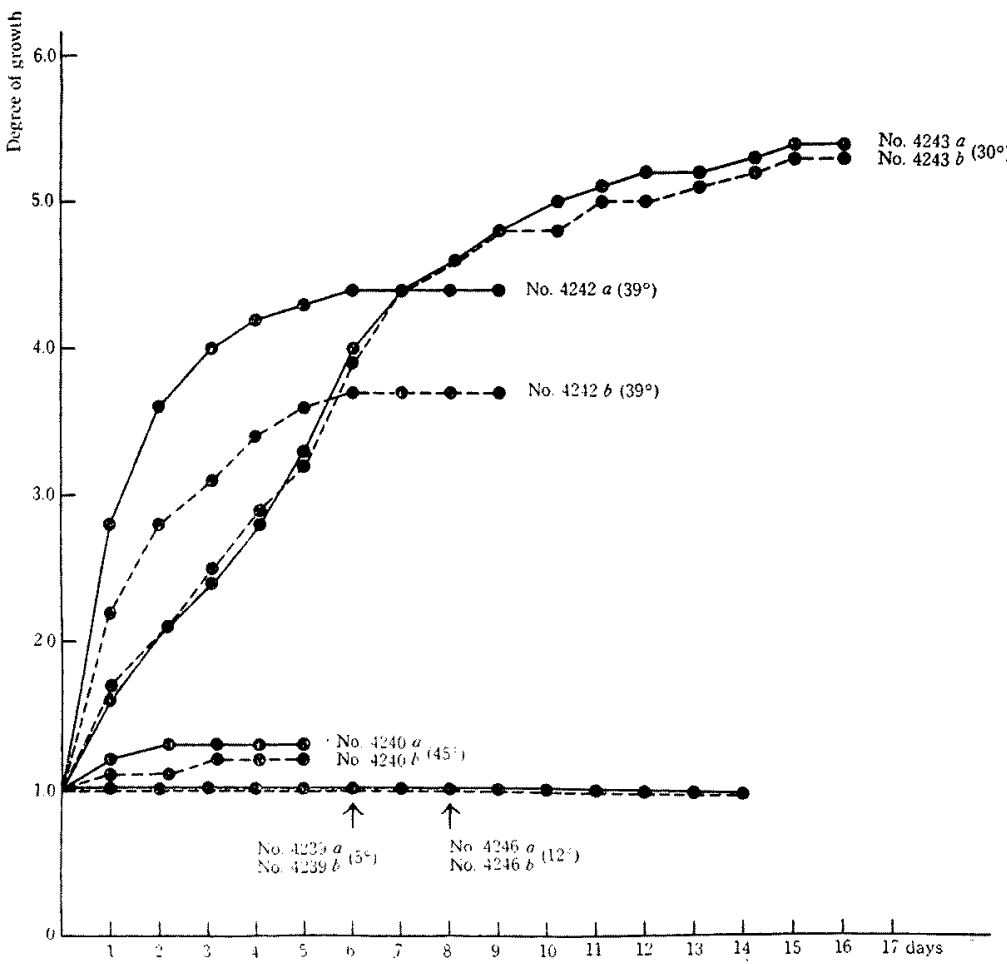

11) A. Fischer, Arch. f. mikroskop. Anat. u. Entw.-mech., 19:5, 104, 221. 


\section{Duration of Life in Vitro in Various Temperatures.}

The life duration in vitro was determined as follows.

After the lapse of a certain length of time the cultures were transferred into a fresh medium and put into an incubator at $39^{\circ}$.

During the next few days, if the transferred tissue cells grew continuously, the culture was considered to be alive, if not, it was reckoned as dead.

Generally if the tissue cells continued to grow till the time, at which the next passage occurred, they grew uninteruptedly after that passage.

Sometimes it was observed that notwithstanding the fact that the tissue cells grew continuously till the time of the new passage, they did not grow at the new passage, probably owing to the fact that the vitality at that time was ton weak to survive the operation of medium changing.

For instance the culture 3463 in $30^{\circ}$ continued to grow, though very slowly, up to the 22nd day, and after the lapse of this interval it was transferred into a fresh medium, but multiplication of the tixue cells was not obserred at all.

On the contrary the opposite phenomena occurred as follows. After the culture attained to its maximum extension and maintained the status quo for a few days, it grew on vigorously in the fresh medium.

For instance, culture 3465 at $30^{\circ}$ reached the maximum width of growth, i. e. $85.9 \mathrm{sq}$. $\mathrm{cm}$, on the fifteenth day and maintained the same width for 6 days, but it grew vigorously in the fresh medium.

Three kinds of observations were made, as follows.-

First, the maximum interval, during which all the fragments, one fragment only, or two together being cultivated in each medium, had been kept alive, was determined.

Secondly the longest life duration for two fragments in each medium and thirdly that in the cases with one fragment was estimated.

(1) $45^{\circ}$.

At $45^{\circ}$ the maximum interval in which all cultures were kept alive, when the medium remained unaltered, was estimated as 1 day. The longest life duration of a single fragment in each medium was noted as 5 days and that in the cases with two fragments in each medium was also appreciated as 5 days as shown in Table III.

At $45^{\circ}$ the difference of the life duration of the cultures with one fragment from that in the cases with two fragments could not be observed.

(2) $39^{\circ}$.

Here Table IV should be referred to. 
On the fifth, sixth and seventh days all the cultures were alive. During this interval they grew on generally without intermission erery day.

On the eighth day, out of 4 examples of the cultures with two fragments 3 died and only one was kept alive. This surviving one grew on till the eighth day, while the other 3 examples ceased to grow on the sixth day. Out of 3 examples of the cultures with one fragment 2 were kept alive and one died.

On the ninth day the cultures with two fragments were kept alive only in one example and died out in the two others. The surriving one cultirated in plate 4032 reached the maximum width on the fifth day and further no augmentation of the area occurred in it, while the two other dead ones grew on till the seventh day. In the cases with one fragment, 2 examples were kept alive out of 5 .

On the tenth day after changing the medium, no growth of the cultures with two fragments was obserred, while the cultures with one fragment were kept alive in one example and died out in one. In plate 860 the culture grew at an increased rate till the tenth day, and in the next passage further augmentation of the area took place.

On the elerenth day, two examples of the cultures with two fragments did not grow in the next new passage, but after changing the medium of the two fragnents in plate 4028 one fragment, in spite of the cessation of growth on the fifth day, was kept alive, while the other was found dead under the same conditions.

On the twelfth day all cultures were dead.

From these data it was observed that the maximum interval, in which all the cultures were kept alive at $39^{\circ}$, when the medium remained unaltered, was estimated as 7 days, the longest of the life duration of a single fragment in each medium was noted as 11 days and that in the cases with two fragments in each medium was found as 9 days.

(3) $30^{\circ}$.

Here Table $\mathrm{V}$ should be referred to.

All the cultures were alive on the eleventh and twelf th day.

On the thirteenth day, out of 3 examples of the cultures with two fragments, only one was alive. The surviving example grew at a slower rate than that of the two other dead examples. The cultures with one fragment were alire in four examples out of six.

On the fourteenth day, two examples of the cultures with two fragments were all alire, while out of 3 examples with one fragment two were alive and one died.

On the fifteenth day, out of 3 examples of the cultures with two fragments, only one was alive; this had grown to a greater extent than the two other examples that died, and two fragments cultirated in it ceased to grow on the twelfth day. The cultures with one fragment had a residual activity in 2 examples out of 4 . One of the dead samples, which was cultivated in plate 2050 , grew at a greater rate than that of the other surviving examples.

On the sixteenth day, out of 4 samples of the cultures with two fragments, only one was kept alive and two died and in the remaining one, which was cultivated in plate 3853 , one fragment survived and the other died. Out of 3 cultures with one fragment, only one was kept alive and the two others were dead.

On the seventeenth day no cultures with two fragments were kept alive, but in plate 3632 one fragment was kept alive and the other died. The former grew more than the latter. Out of $s$ cultures with one fragment, only one was kept alive and the two others died. 
On the eighteenth day all the cultures with two fragments died, while out of 5 examples of the cultures with one fragment, two were kept alive.

On the nineteenth day all the cultures with two fragments died, while out of 4 examples of the cultures with one fragment only one was kept alive, progressively augmenting its area until the nineteenth day.

On the twentieth day the culture with two fragments did not grow after the next passage, but out of 2 examples of the cultures with one fragment, one was kept alive and the other died. The former reached its maximum width on the fifteenth day and ceased to grow for 6 days.

On the twenty first day all the cultures, with one or two fragments, could not be kept alive, though they continued to grow on till the twentieth day except one example which was cultivated in plate 3475 , the tissue fragment growing in it till the twenty first day.

On the twenty second and third days no cultures conld be kept alive. No further obserration was made.

On the whole at $30^{\circ}$, the maximum interval, during which all the fragments were kept alive, when the medium remained unaltered, was estimated as 12 days, the longest life duration of one fragment in each medium was noted as 20 days and that in the cases with two fragments in each medium was found as 16 days.

(4) $20^{\circ}$.

On the whole at $20^{\circ}$, the maximum interval, during which all the fragments were kept alive, when the medium remained unaltered, was estimated as eleven days, the longest life duration of one fragment in each medium was noted as 14 days and that in the cases with two fragments in each medium was found as 12 days.

$\mathrm{F}$ ischer $\mathrm{r}^{4}$ was able to keep tissues in vitro at the rom temperature $\left(20^{\circ}\right)$ at least three weeks without changing the medium, but the results of my cases did not agree with his and it was found as above mentioned that the fibroblast in vitro remained alive at $30^{\circ}$ rather longer than at $20^{\circ}$ in the unaltered medium.

(5) $12^{\circ}$

On the whole at 12 the maximum interval, in which all the cultures were kept alive, when the medium remained unaltered, was estimated as 6 days, the longest life duration of one fragment in each medium was noted as 11 days and that of two fragments in cach medinm was found as 7 days.

(6) 5 .

On the whole, at $5^{\circ}$ the maximum interval, in which all the cultures were kept alive, when the medium remained unaltered, was estimated as 3 days, the longest life duration of one fragment in each medium was noted as 8 days and that in the cases with two fragments in each medium was found as 7 days. 
Generally the life duration of the fibroblast in the unaltered culture medium was longer in the cases where one fragment was cultivated in one medium, than in the cases where two cultivated together. This might be attributed in the cases of $39^{\circ}$ and $30^{\circ}$ to the circumstances already considered (p. 625), that is, the lack of oxygen in the culture chamber or the rapid accumulation of metabolic products, but it was difficult in the cases of $20^{\circ}, 12^{\circ}$ and $5^{\circ}$ not only to assume the same causes, but also even to decide whether it was an essential phenomenon or rather, an accidental one, as the experimental numbers were few. Fig. 2 illustrates the relation above mentioned between the life duration and the temperature.

Fig. 2.

The maximum interval of the life duration of the cuttures in vitro at rarious temperatures, when the medium remained unattered.

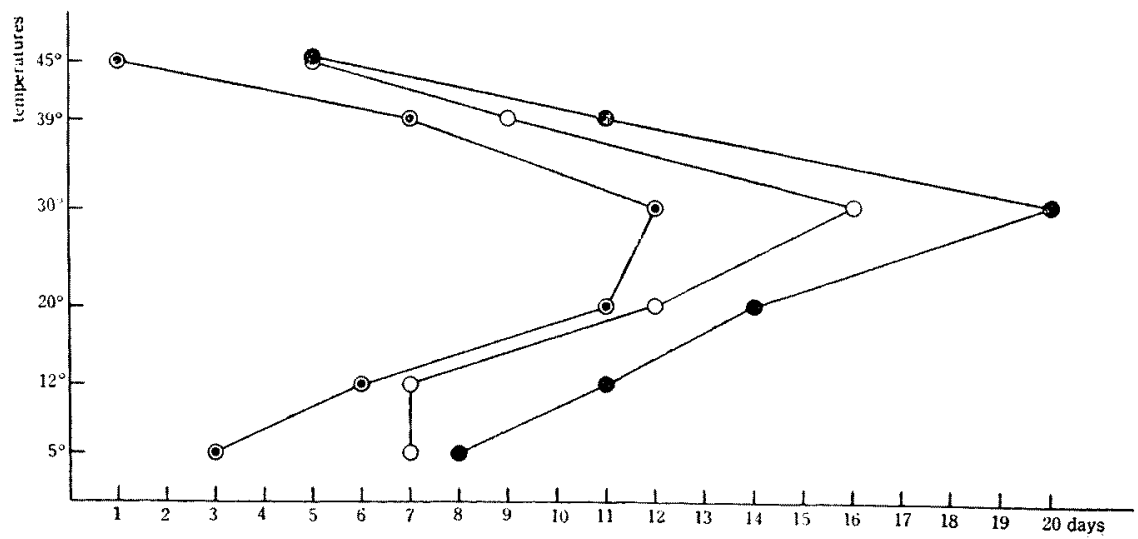

$\multimap$ The maximum interval during which every fragment was surely kept alive.

- - The longest interval during which two fragments cultivated together were kept alive.

The longest interval during which one fragment cultivated in one medium was kept alive.

\section{Temperature Coefficient.}

(1) The Degree of Growth.

Development and growth of some plants and animals have often been the objects of investigation of temperature effect, and the relations between them have usually been expressed by the number calculated according to 
van't Hoff's ${ }^{12}$ formula (Temperature coefficient) or to A rrhenius's ${ }^{13)}$ (Temperature characteristic $\mu$ after Crozier) ${ }^{15)}$ as more theoretical.

Many workers seem to be inclined to recognize the coincidence between the results and these laws within certain limits of temperature, though some refuse to accept it (Krough, Bucciante, and Bayliss). ${ }^{15}$ )

To contribute to the problem of tissue growth in vitro, I calculated the temperature cocfficient $\left(Q_{10}\right)$ as a measure of temperaturc effect on the tissue growth.

It would be ideal ${ }^{16)}$ for such study to see pieces of tissue which consisted of parts of one fragment and to treat them in a quite identical manuer except as regards the temperature to be studied. But as I could not get a sufficient number of pieces to distribute into the various temperatures, I used the fragments from different cultures but of the same origin.

As the cultures kept at $20^{\circ}, 12^{\circ}$ and $5^{\circ}$ did not show any growth at all, I excluded them from the culculation.

a) First, when the cultures with one fragment were inoculated in cach medium, the $Q_{10}$ values obtained between $45^{\circ}$ and $39^{\circ}$ were estimated as 0.5 to 0.2 , the largest being on the first day and diminishing gradually day by day, as shown in Table IX.

The fact that the $\mathrm{Q}_{10}$ values were smaller than unity showed that the more adequate temperature than $39^{\circ}$ for the growth of the tissue cells in vitro did not exist between $45^{\circ}$ and $39^{\circ}$.

In the same cases the temperature coefficients obtained between $39^{\circ}$ and $30^{\circ}$ oscillated from 1.2 (groups I and II) to 5.8 (group IV). But in group II, from the second day till the seventh, and in group $V$ from the second till the last the $\mathrm{Q}_{10}$ values were 2.0-2.4, coinciding with that of van't Hoff's law.

From the second day the $\mathrm{Q}_{10}$ values augmented by slow degrees and they reached the maximum in a few days, i. e. on the fifth day at latest as shown in group $\mathrm{V}$.

12) T. Loeb, Pflüger's Arch., 190S, 124, 411; J. Loeb and H. Wasteneys, Biochem. Zeitschr. 1911, 36, 345; A. Krough, Zeitschr. f. allgen. Physiol., 1914, 16, 163 and 178; L. A. Brown, Proc. of the Soc. of Exp. Biol. and Med., 1927, 25, 164; L. Buccian te, Arch. f. exp. Zellforsch., 1927, 5, 1.

13) Ch. I. Bliss, Journ. gen. Physiol, 1926, 9, 467; L. A. Brown, Journ. gen. Physiol., 1927, 10, 111.

14) W. J. Crozier, Journ. Gen. Physiol, 1925, 7, 124.

15) W. M. Bayliss, Principles of general physiology, (London) 1924, 42.

16) A. H. Ebeling, Journ. Exp. Med., 1921, 34, 233. 


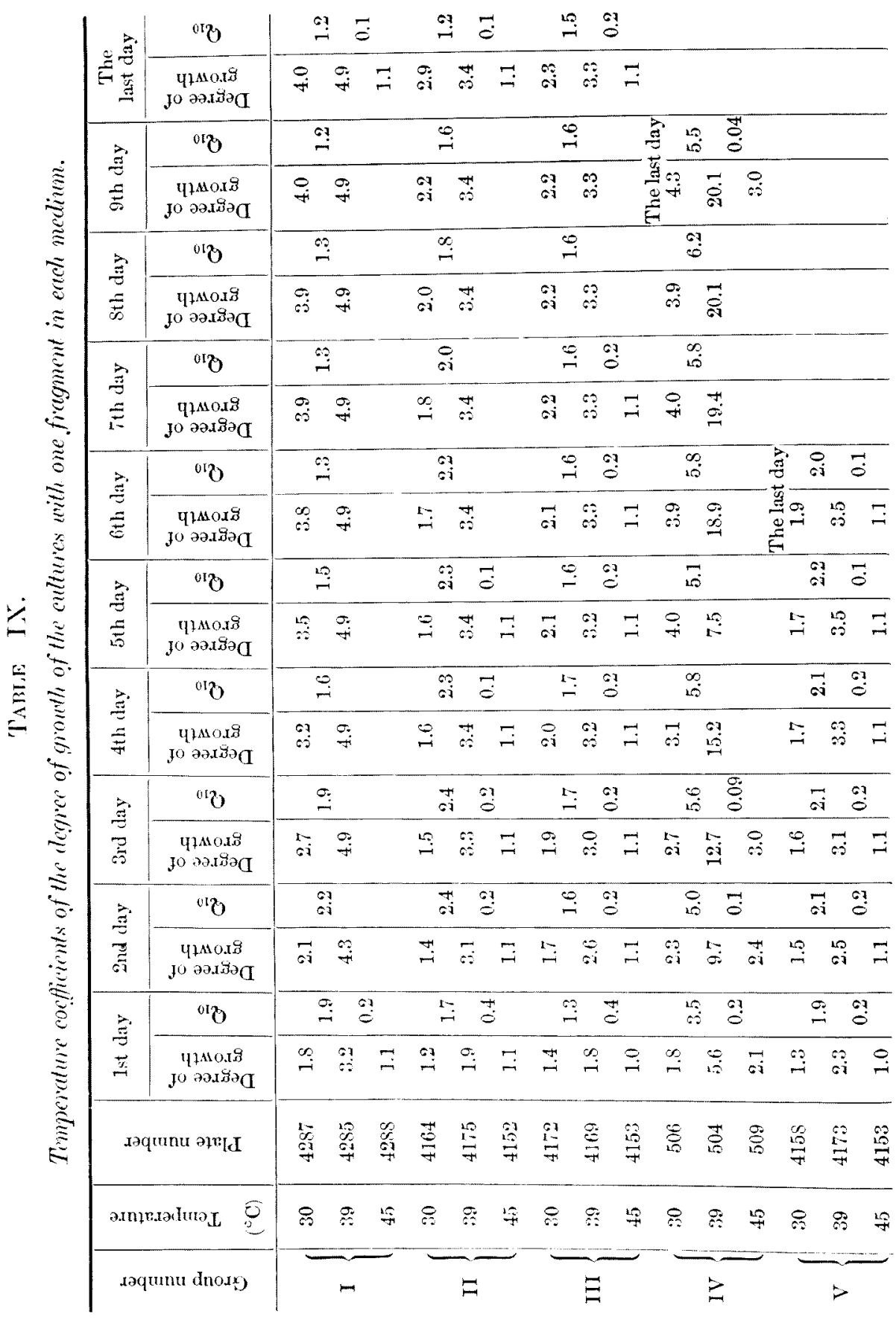


The interval of time, during which the $Q_{10}$ values coincided with that of van't Hoff's law consisted in the period during which the cultures in the incubator at $39^{\circ}$ grew at a greater rate until the arrival at the maximum width.

As the cultures at $39^{\circ}$, after the arrival at the maximum growth, maintained the same areas for a few days and the cultures at $30^{\circ}$ continued to grow during the same period, the $\mathrm{Q}_{10}$ values diminished gradually, but did not become so small as unity.

b) Secondly, when the cultures with two fragments were inoculated in each medium the $\mathrm{Q}_{10}$ values obtained between $45^{\circ}$ and $39^{\circ}$ were found as 0.7 to 0.1 , as is represented in Table $X$.

In this interval of temperature no difference was observed, whether one fragment was cultivated in each medium or two together.

In the cases between $39^{\circ}$ and $30^{\circ}$ the $\mathrm{Q}_{10}$ values were estimated as 1.9-0.6.

They were markedly smaller than those in the cases with one fragment.

This fact demonstrated again that the degree of growth at $39^{\circ}$, when two fragments were cultivated together, was smaller than that in the cases where a single one was cultivated, as the degrees of growth at $30^{\circ}$ were not essentially different from one another whether one was or two together were cultivated in one medium (Tables IV-V).

The $\mathrm{Q}_{10}$ values in these cases were largest at the first day, with some exception, and diminishce gradually as the days of the life in vitro advanced.

If the growth of tissue at $39^{\circ}$, two fragments being cultivated together, had ceased owing to the consumption of the fool material and oxygen in the medium, and the degree of growth had depended upon these materials only, one would have expected to find that the degree of growth at $30^{\circ}$ would have been at most the same, and the life duration in both cases after the maximum growth would not have been so much different from each other. But it was not always the case.

In some examples the $\mathrm{Q}_{10}$ was smaller than unity, that is the ultimate degree of growth was there smaller at $39^{\circ}$ than at $30^{\circ}$.

This suggests that too rapid accumulation of metabolic products, thongh the absolute quantity of which be the same at $39^{\circ}$ and $30^{\circ}$, ultimately injures the activity of the tissue in vitro. But as the samples were very few, I had to refrain from deducing any definite conclusion. 


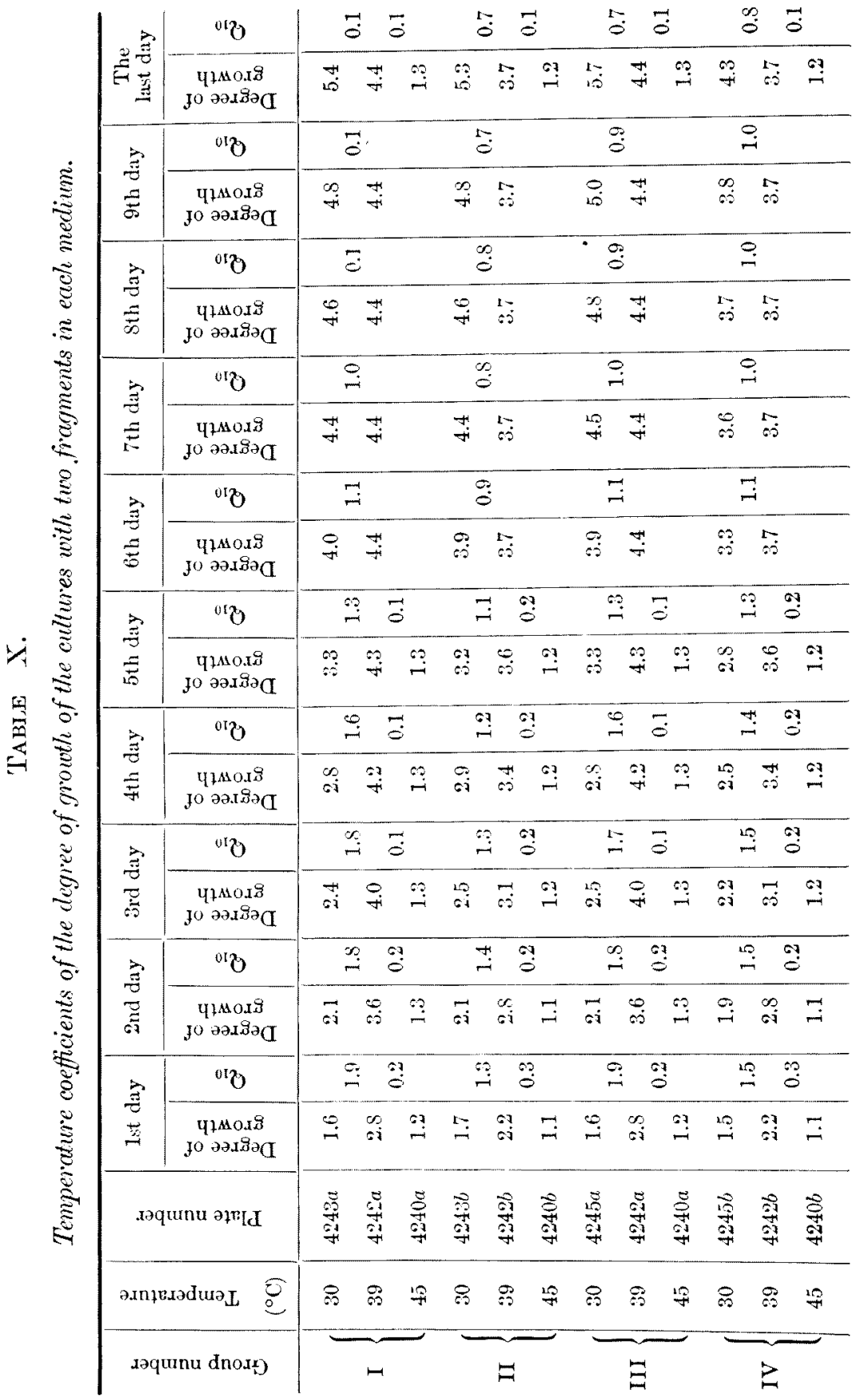


Influence of Temperature upon Life \& Growth of Fibroblast

25

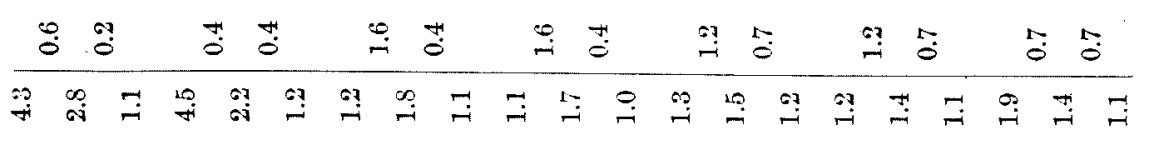

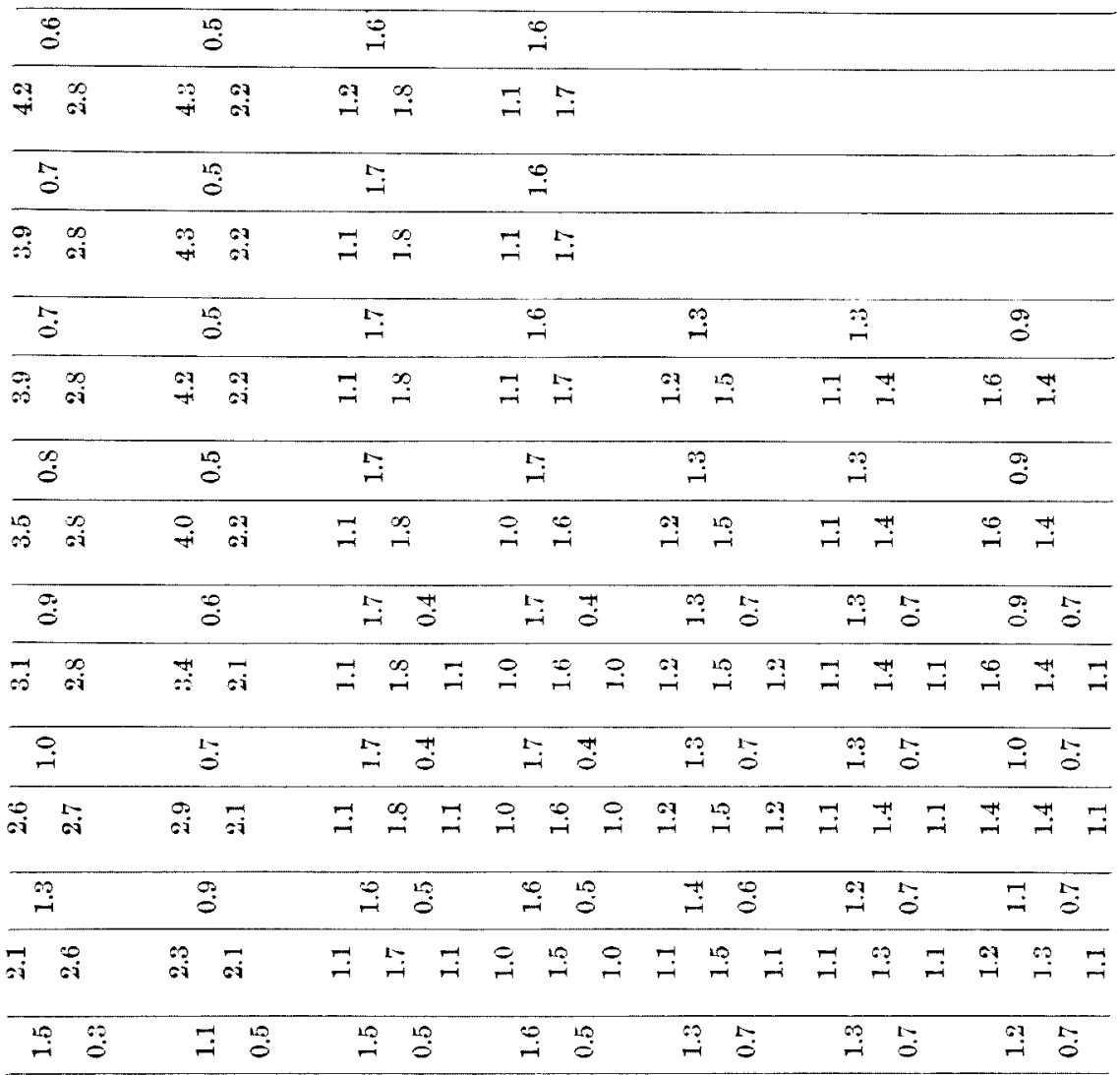

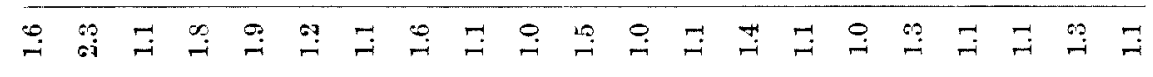

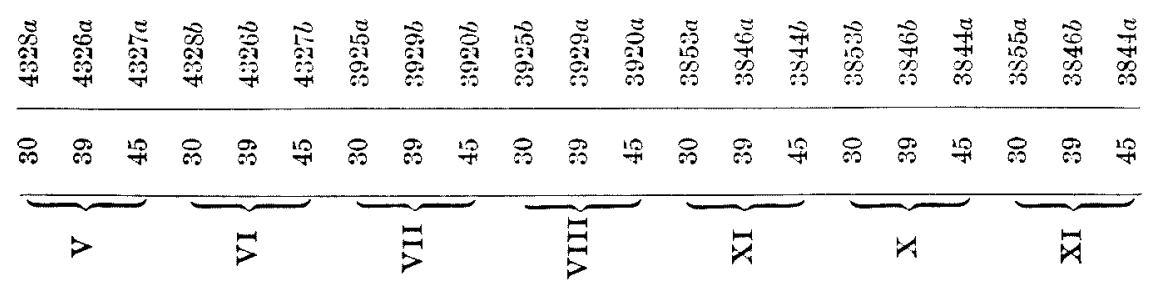




\begin{tabular}{|c|c|c|}
\hline \multirow{2}{*}{ 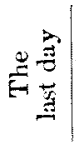 } & 0 & $\because \tilde{0}$ \\
\hline & 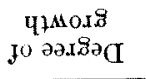 & $\overline{a j} \stackrel{19}{-i} \stackrel{9 !}{-}$ \\
\hline \multirow{2}{*}{$\begin{array}{l}\vec{z} \\
\stackrel{\Xi}{\Xi}\end{array}$} & 3 & \\
\hline & 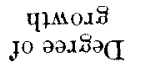 & \\
\hline \multirow{2}{*}{$\begin{array}{l}\overrightarrow{\vec{Z}} \\
\overrightarrow{\vec{D}}\end{array}$} & 2 & \\
\hline & 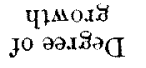 & \\
\hline \multirow{2}{*}{$\vec{\Xi}$} & 18 & \\
\hline & $\begin{array}{c}\text { ч1.110.13 } \\
\text { jo əə.1Səव }\end{array}$ & \\
\hline \multirow{2}{*}{ 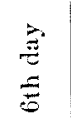 } & 20 & $\stackrel{\infty}{\varrho}$ \\
\hline & 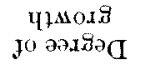 & $\stackrel{10}{-}$ \\
\hline \multirow{2}{*}{$\begin{array}{l}\stackrel{3}{*} \\
\stackrel{5}{5}\end{array}$} & $\%$ & $\stackrel{\infty}{\ominus}$ \\
\hline & 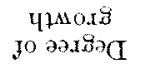 & $\stackrel{\infty}{\rightarrow}$ \\
\hline \multirow{2}{*}{$\begin{array}{l}\stackrel{3}{ت} \\
\stackrel{\Xi}{\Xi}\end{array}$} & $\%$ & 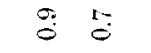 \\
\hline & 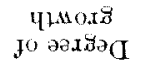 & $\stackrel{2}{-} \stackrel{2}{-} \stackrel{9}{-}$ \\
\hline \multirow{2}{*}{$\begin{array}{l}5 \\
\Xi \\
5 \\
5\end{array}$} & $\%$ & $\stackrel{9}{\circ}$ \\
\hline & 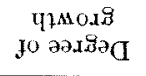 & $\stackrel{29}{-9}$ \\
\hline \multirow{2}{*}{ 莣 } & $\%$ & $\stackrel{\leftrightarrow}{\oplus} \stackrel{0}{0}$ \\
\hline & 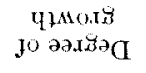 & 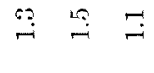 \\
\hline \multirow{2}{*}{$\begin{array}{l}3 \\
\stackrel{3}{*}\end{array}$} & 010 & $\stackrel{?}{-1}$ \\
\hline & 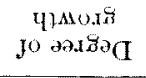 & 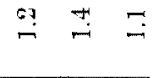 \\
\hline \multicolumn{2}{|c|}{ xәquntr әfग्Id } & 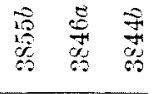 \\
\hline \multicolumn{2}{|c|}{ 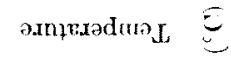 } & $8 \%$ \% \\
\hline \multicolumn{2}{|c|}{ səqunu dnoxs) } & 5 \\
\hline
\end{tabular}

\section{(2) Duration of Life in Vitro.}

Loe $b^{12}$ found an extraordinarily large figure for the temperature coefficient (1000) of life duration with eggs of Strongylocentrotus purpuratus, but later with Northrop, ${ }^{17)}$ using aseptic Drosophila found the value corresponding to van't Hoff's law.

My results re temperature coefficient of life duration of the fibroblast in vitro in an unaltered medium are shown in Table XI.

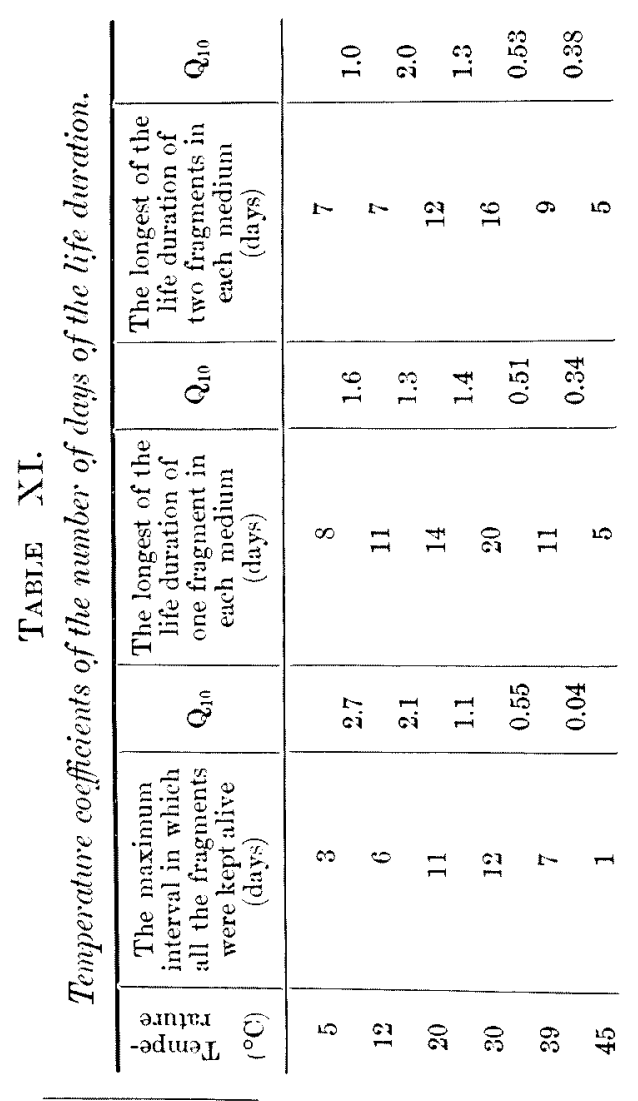

17) T. Loeb and J. II. North rop, Journ. Biol. Chem., 1917, 32, 104. 
For the maximum intervals, during which all the fragments were kept alive at various temperatures, i. e. $5^{\circ}, 12^{\circ}, 20^{\circ}, 30^{\circ}, 39^{\circ}$ and $45^{\circ}$, the $Q_{10}$ values coincided with that of van't $H$ of $f^{\prime} s$ law only in the ranges of temperature from $5^{\circ}$ to $12^{\circ}$ and from $12^{\circ}$ to $20^{\circ}$.

As the temperature became higher, the more $Q_{10}$ values diminished.

In the longest life duration of one fragment in each medium the temperature coefficient coincided with that of van't Hoff's law only between $5^{\circ}$ and $12^{\circ}$.

In the cases of two fragments in each medium the highest value existed between $12^{\circ}$ and $20^{\circ}$ and was estimated as 2.0 .

\section{SUMnary.}

(1) The fragments of heart muscle of the chicken embryo incubated at $39^{\circ}$ for 8 or 9 days were embedded in the culture medium, composed of equal volumes of the hen plasma and the embryonic tissue juice.

All the cultures underwent 5 or 7 passages and then were kept in the incubator $39^{\circ}$ for one day.

Then the plates with the tissue fragments were placed in the incubators at various tenuperatures, i. e. $45^{\circ}, 39^{\circ}, 30^{\circ}, 20^{\circ}, 12^{\circ}$ and $5^{\circ}$. In every medium one fragment was cultivated or two together. The outline of the total area of the new cells was traced every day, thus the degree of growth at various temperatures was determined. After the lapse of a certain length of time the culture was transferred into a fresh medium and put into an incubator at $39^{\circ}$, to determine whether the tissue was living or not.

(2) The degree of growth was largest at $39^{\circ}$, the next at $30^{\circ}$ and the smallest one was found at $45^{\circ}$.

The tissue kept at $20^{\circ}, 12^{\circ}$ and $5^{\circ}$ did not grow at all.

(3) In the cases where one tissue fragment was cultivated in one medium, the temperature coefficients of the degree of growth at 39 and $30^{\circ}$ were 2.0-2.4 in the interval of a few days, during which the tissues continued to grow both at $39^{\circ}$ and $30^{\circ}$. The $Q_{10}$ values between $45^{\circ}$ and $39^{\circ}$ were smaller than unity $(0.5$ to 0.2$)$ and diminished as the life duration in vitro advanced.

(4) In the cases with two fragments in each medium the $Q_{10}$ values were smaller than those of the above between $39^{\circ}$ and $30^{\circ}$ and sometimes after a few days' life in vitro it became smaller than unity. Between $45^{\circ}$ and $39^{\circ}$ it was the same as that with one fragment in each medium.

(5) The maximum interval, in which all the fragments were kept 
alive, when the medium remained unaltered, was estimated as 1 day at $45^{\circ}$, 7 days at $39^{\circ}, 12$ days at $30^{\circ}, 11$ days at $20^{\circ}, 6$ days at $12^{\circ}$ and 3 days at $5^{\circ}$.

The longest life duration for one fragment in each medium was noted as 5 days at $45^{\circ}, 11$ days at $39^{\circ}, 20$ days at $30^{\circ}, 14$ days at $20^{\circ}, 11$ days $12^{\circ}$ and 8 days at $5^{\circ}$, and that in the cases with two fragments 5 days at $45^{\circ}, 9$ days at $39^{\circ}, 16$ days at $30^{\circ}, 12$ days at $20^{\circ}, 7$ days at $12^{\circ}$ and 7 days at $5^{\circ}$.

(6) The temperature coefficients of the number of days of life duration were the highest at low temperature $\left(2.0\right.$ between $20^{\circ}$ and $\left.12^{\circ}\right)$ and the more temperature was heightened, the smaller they became. 